\title{
MODA/INDUMENTÁRIA EM CULTURAS JUVENIS: SÍMBOLOS DE COMUNICAÇÃO E FORMAÇÃO DE IDENTIDADES CORPORAIS PROVISÓRIAS EM JOVENS DO ENSINO MÉDIO
}

\section{JUVENILE CULTURES' FASHION/CLOTHING: COMMUNICATION SYMBOLS AND TEMPORARY BODY IDENTITIES' CREATION ON HIGH SCHOOL TEENS}

\author{
Ms. Antonio Galdino da Costa \\ Centro Federal de Educação Tecnológica de Santa Catarina \\ Dr. Giovani De Lorenzi Pires \\ Universidade Federal de Santa Catarina
}

\begin{abstract}
Resumo
Essa pesquisa teve como objetivo compreender a comunicação nas culturas juvenis, expressa por meio dos símbolos da moda/indumentária e adereços no ambiente escolar, levando em conta as questões socioculturais dos alunos, seus diferentes grupos e culturas. Evidenciar a existência destes grupos nos espaços escolares parece ser de suma importância, para que assim a escola possa promover formas de interação e reconhecimento. $\mathrm{O}$ que a pesquisa aponta é a necessidade de a escola perceber o jovem como sujeito do seu cotidiano, inclusive o escolar, não se limitando a estipular normas, nem reconhecê-lo apenas no espaço/tempo das aulas, pois nos demais espaços escolares os jovens também comunicam suas identidades, constituem seus grupos e se reconhecem neles.

Palavras-Chave: Moda/Indumentária; Culturas juvenis; Comunicação; Identidades corporais.

\section{Introdução}

O problema e sua importância

A temática de que trata este estudo surgiu da inquietação em tentar compreender um pouco mais o cotidiano das culturas juvenis para além do tempo/espaço da sala de aula. A pesquisa se desenvolveu na perspectiva de saber como se constituem os grupos, com as suas respectivas identidades, como os alunos se integram (ou não) a esses
\end{abstract}


grupos, a partir de suas identidades corporais provisórias, e quais símbolos comunicacionais contribuem para esse processo.

Para levar a cabo uma investigação desse tipo, é preciso ver o jovem-aluno dialeticamente, na sua individualidade e no seu pertencer ao grupo. E também perceber grupos cuja dimensão e forma de constituição são diferentes da turma de aula, grupo que a escola constitui, percebe e controla. Para Sacristán (1999, p. 47), “sem atender aos significados dos sujeitos não se pode entender os fenômenos culturais e sociais concernentes à educação". O jovem-aluno traz para o contexto escolar todo um processo de humanização, sua cultura, seus saberes.

O fazer escolar é quase sempre voltado para o processo ensino-aprendizagem, focado principalmente na sala de aula (ou no laboratório, na quadra etc.) e limitado aos saberes institucionalizados, apropriados e transmitidos pela escola. São desprezadas outras dimensões igualmente importantes da experiência humana, tais como as relações interpessoais, os princípios éticos e os valores estéticos.

Uma das posturas mais sistemáticas da escola é desconsiderar os grupos que são formados autonomamente pelos alunos e até desorganizá-los, quando o grupo, na visão da escola, interfere nos propósitos escolares. A escola estabelece certas normas e exige seu cumprimento.

Em nosso entendimento, a escola precisa conhecer um pouco mais o cotidiano da juventude - ou melhor, juventudes - para poder intervir, atuar e interagir com os alunos, e não contra os alunos, também a partir de suas realidades, de seus momentos de convívio no ambiente escolar, de suas falas, de seus grupos e de suas diferentes formas de interação. De acordo com Dayrell (2005, p. 115), "o grupo significa um espaço de aprendizagem e de aprimoramento pessoal, um dos poucos espaços coletivos em que há aprendizagem de relações de confiança coletivas". Conhecer o cotidiano dos alunos em seus grupos é importante para que a escola possa compreender um pouco mais sobre a vida destes alunos, para além da sala de aula.

A formação dos grupos acontece pelas diferentes formas de comunicação que mediam os nossos atos, como um fenômeno humano. Entre outras, estão as identidades 
corporais que, como símbolos de comunicação, facilitam a aproximação e a construção dos grupos com seus diferentes significados.

A comunicação é a primeira forma de sermos interpretados. Mas o comunicarse é um processo muito mais amplo e complexo do que a rotina escolar consegue abranger. Certas convenções que comunicam intensamente, como as roupas e adereços, estão muito além da compreensão da escola, apesar de "visitarem” seus domínios. Sob este aspecto, para a escola existe tão-somente o uniforme, a subjugar formas simbólicas de comunicação. Moda/indumentária talvez seja um dos elementos de maior visibilidade na atualidade.

Como decorrência disso, um dos pontos que pode ser observado na constituição dos grupos é o uso da moda/indumentária como símbolo de comunicação. Os grupos formados, muitas vezes, distinguem-se pelas cores e modelos de vestimenta, que funcionam como símbolos de identificação corporal provisória.

Esse corpo, que Trebels (2003) denomina relacional (em oposição ao corpo meramente substancial, físico), é o ponto de referência, pois ele vai portar os símbolos de comunicação que construirão a sua visibilidade e sua identificação com o grupo. Para Baitello Júnior (2000), as formas de comunicação sempre começam com o corpo, que é por ele denominado "mídia primária". A comunicação corporal envolve múltiplas formas de expressividade: o andar, a postura, os movimentos da cabeça, os olhos, o enrugar da testa, etc.

De acordo com o mesmo autor, a "mídia secundária" é constituída por objetos máscaras, adereços, roupas, imagens, pinturas etc. - usados para representar a mensagem. Tal como a mídia primária, a mídia secundária é também crucial na construção da identidade. Atualmente são feitas várias intervenções sobre o corpo, de forma que ele se torne um objeto da moda.

A vestimenta, portanto, gera códigos específicos e, nessa medida, ela expressa a identidade dos grupos e classes sociais. De acordo com Lurie (1987), as roupas e adereços são formas de a sociedade se comunicar e assim ter um diferencial para poder constituir os grupos e manter as ideologias. 
A influência da moda/indumentária sobre o cotidiano das culturas juvenis, considerando seu papel como um símbolo comunicacional, possibilita compreender melhor como essa forma de comunicação acontece no espaço escolar, especialmente no que se refere à formação de grupos, ao estabelecimento de relações sociais e à busca do pertencimento.

Assim, o objetivo principal desta pesquisa foi o de compreender a comunicação nas culturas juvenis, expressa por meio dos símbolos da moda/indumentária e adereços no ambiente escolar, levando em conta as questões socioculturais dos alunos, seus diferentes grupos e culturas, que podem ser comunicados em diferentes espaços na escola, também por meio das formas simbólicas.

Neste sentido, procuramos analisar as questões relacionadas à juventude na perspectiva de um universo mais amplo, como uma categoria sociológica e historicamente construída (PAIS, 1993), e assim tentamos dar conta dos objetivos que propomos para esta investigação. Toda a complexidade inerente à categoria culturas juvenis pode ser exposta na seguinte pergunta de partida: quais os significados comunicacionais que subjazem às identidades corporais provisórias dos jovens no âmbito escolar, expressas na moda/indumentária?

Como decorrência dessa preocupação e como forma de subsidiar a reflexão sobre o problema da pesquisa, seguimos algumas questões de investigação, que foram assim formuladas:

- Como moda/indumentária podem ser percebidas como símbolos de comunicação na escola?

- É possível reconhecer tais símbolos como facilitadores para a formação de novos grupos de alunos recém-chegados à escola?

- Como estes símbolos são percebidos e significados pelos jovens-alunos?

- O espaço escolar pode contribuir para a formação das identidades corporais provisórias, através da moda/indumentária? 


\section{O percurso metodológico}

O contexto da pesquisa foi o Centro Federal de Educação Tecnológica de Santa Catarina, Unidade São José, na região da grande Florianópolis, a partir da primeira semana de aula dos alunos, quando da chegada destes na escola, no começo do semestre letivo de 2005/1. A parte observacional do campo desenvolveu-se entre o dia 08 de abril e 03 de junho/2005, num total de dezesseis observações/dia. Os encontros dos grupos focais deram-se de 20 de junho a 15 de julho/2005.

A pesquisa foi realizada com uma turma de primeira fase, com todos os alunos (32) recém-chegados à escola. Nesta pesquisa, as denominações jovens, jovens-alunos, sujeitos, culturas juvenis, juventudes são todas usadas para nos referirmos a esta população específica, que se fez presente em todos os momentos da pesquisa e deve ser tratada no plural, como nos ensinam Dayrell (2005), Pais (1993) e Castro e Abramovay (2003).

Quanto ao tipo de estudo que foi desenvolvido, pode-se caracterizá-lo como uma observação participante, que se propôs a descrever e interpretar aspectos da comunicação simbólica, expressos na moda/indumentária e adereços, e sua implicação na constituição de grupos sociais dentro de um recorte específico do cotidiano cultural juvenil (âmbito escolar), a partir de aspectos do método proposto por Thompson (1995), que é a hermenêutica de profundidade.

A denominação dos grupos foi feita em alusão à forma como a área da moda/indumentária tratam suas linhas de produção de acordo com os estilos e as estações. Trata-se de denominação ad hoc, que não tem a pretensão de rigor científico. São elas: Fashion, Sportwear, Street Wear, Moda Rock e Jeanswear.

Notas diversas, reconstrução de diálogos e outras observações do pesquisador foram registradas em um diário de campo, que, juntamente com as fotografias, serviram para fornecer subsídios para a continuidade da pesquisa. Os cinco grupos referidos, formados de maneira autônoma pelos estudantes, no cotidiano escolar, e identificados pela observação participante, foram instituídos como grupos focais da pesquisa. 
A opção pela técnica dos grupos focais deu-se pelo fato de que, ao permitir a focalização temática, ela possibilita o aprofundamento das reflexões e discussões entre os sujeitos da pesquisa, mediadas pelo próprio pesquisador. Assim, a interpretação dos dados foi feita a partir dos textos constituídos pelos registros das observações de campo e dos depoimentos dos grupos focais, tendo as fotos como suporte técnico.

Para a análise de conteúdo, trabalhamos com eixos temáticos que foram identificados num duplo movimento: por se constituírem em trama das questões de investigação e, por isso, serem utilizados também como tópicos do roteiro dos diálogos nos grupos focais. Assim, os eixos temáticos tiveram sua definição (provisória) preliminarmente às observações do campo; todavia, o campo veio confirmar a pertinência das temáticas preestabelecidas, sendo que mais um eixo temático (referente ao preconceito), surgiu no campo.

Foram definidos seis eixos temáticos que são nomeados a seguir:

a) Aproximações e a formação do grupo: encontros $e$ desencontros;

b) Interesses comuns: caracterização e identificação como grupo;

c) Identidades corporais provisórias: moda/indumentária como facilitador para a formação dos grupos;

d) Outros símbolos comunicacionais e identitários: os adereços;

e) O uniforme escolar: disputa e negação de identidade;

f) Moda/indumentária das diferenças: a presença (nem sempre) sutil de preconceitos. 


\section{QUADRO TEÓRICO DE REFERÊNCIA}

Todas as sociedades, desde aquelas que se organizam da forma mais simples às mais complexas, possuem diferentes formas e canais de comunicação: da fala à escrita; do corpo aos gestos; das roupas, adereços e artefatos às imagens. A linguagem surge a partir da necessidade humana de se comunicar. Cada uma dessas formas de emissão/recepção de mensagens possui símbolos próprios, e assim, as mensagens que circulam só podem ser compreendidas conhecendo-se o conjunto das práticas sociais, dos valores e da percepção de mundo da sociedade que os criou. Para Aguiar (2004, p. 56-57)

[...] a linguagem verbal $\mathrm{e}$ as linguagens não verbais compõem-se de códigos globais que abrigam inúmeros subcódigos relacionados entre si e responsáveis por tipos de comunicação diferentes, segundo as funções que queremos privilegiar. Logo, as linguagens devem ser estudadas em toda a variedade de suas funções.

As diversas linguagens se entrecruzam na sociedade moderna, num determinado espaço e tempo, e é nesta sincronia comunicacional que se podem encontrar os códigos de cada linguagem, seus símbolos, seu suporte de emissão de mensagens, os seus sentidos, os autores e para quem se destinam as mensagens, é a segmentação baseada nas classes sociais, além de outros traços sociais distintivos. As formas de linguagem mudam de acordo com a situação que vivemos e as necessidades de comunicação que enfrentamos.

Vivemos atualmente, segundo Abad (2003), a "juvenilização da cultura”. O ser jovem tornou-se muito valioso, pois a juventude é um produto que tem grande mercado. Com isso, a incorporação dos símbolos que identificam a cultura juvenil tem um valor inestimável, independentemente da idade do portador do símbolo.

Nas culturas juvenis, os espaços propícios para a formação de novos grupos, de convívio sem as rígidas regras que são impostas pela sociedade, podem ser percebidos nos momentos de lazer. O lazer é um espaço/tempo para o desenvolvimento de relações de sociabilidade, de troca de experiências e de vivências, por meio das quais os jovens 
procuram estruturar novas formas de identidades individuais ou coletivas. Para Soares. (2004, p. 137), a construção da "identidade é necessariamente um processo social, interativo, de que participa uma coletividade e que se dá no âmbito de uma cultura e no contexto de um determinado momento histórico". O espaço de lazer não segue as formalidades da escola ou da família, é um campo em que o jovem pode expressar seus desejos e mesmo tentar encontrar um outro modo de vida, e consequentemente construir suas identidades provisórias. Segundo Pais (1993, p. 159), “é no domínio do lazer que as culturas juvenis adquirem maior visibilidade e expressão". Também para Brenner, Dayrell e Carrano (2005, p. 176), "é principalmente nos tempos livres e nos lazeres que os jovens constroem suas próprias normas e expressões culturais, ritos, simbologias e modos de ser que os diferenciam do denominado mundo adulto". Para Abramo (1994, p. 62), o lazer "é uma das dimensões mais significativas da vivência juvenil".

A inserção de um indivíduo em uma comunidade se dá essencialmente por meio da comunicação. A comunicação entre os indivíduos os torna membros de grupos culturais comuns. Mas a comunicação é troca e produção de significados. Assim, as roupas podem ser usadas como códigos comunicativos. Para Barnard (2003, p. 55), "é a interação social, por meio da indumentária, que constitui o indivíduo como um membro do grupo, e não vice-versa, ser um membro do grupo e então interagir socialmente". Esta situação pode ser vista principalmente nos grupos tidos como diferentes em nossa sociedade. Por exemplo, os skinheads vestem-se "a caráter" para pertencer ao grupo e não ao contrário. Como diz Castilho (2004, p. 83), "a imagem que um sujeito cria de si mesmo exprime-se, então, em codificações, em seu modo de parecer, de mostrar-se para ser visto".

Assim, a moda se faz presente na sociedade contemporânea, indiferentemente das classes sociais, pois há produtos disponíveis para o consumo de todas as classes. $\mathrm{O}$ que muda são os valores. A moda/indumentária marca sua presença junto aos jovens, o que não poderia ser diferente, pois estes constituem um segmento importante na cultura de consumo; são, ao mesmo tempo, produtos da própria cultura de consumo, que tem como objetivo a juvenilização da sociedade. A importância desta fatia da população 
decorre do fato de que seus padrões de consumo inspiram produtos para os demais grupos etários e sociais. Com a juvenilização da sociedade moderna, o fenômeno da cultura de consumo se fortalece ao manter as distinções sociais. O consumo produz o prazer e a satisfação em poder exibir as aparências e assim sustentar os valores estéticos e a realização dos sonhos e desejos do imaginário social consumista.

\section{RETRATOS DO CAMPO}

O cotidiano da turma quanto à movimentação dos alunos no espaço escolar foise constituindo ao longo do período de observação e acompanhamento. Nos primeiros dias, os alunos se deslocavam meio alheios ao ambiente, como se procurassem seus pares. Alguns alunos já se conheciam, pois provinham da mesma escola do ensino fundamental. Com o passar dos dias, os alunos foram se aproximando e formando seus grupos, e consolidando os já existentes. Tanto na sala quanto nos demais locais da escola, os espaços começaram a ser ocupados, transformando-se nos "pedaços" dos grupos, conforme apareceu no trabalho, a partir da observação e das fotografias da turma em seu cotidiano escolar. Foi possível ver as coincidências (ou não) com que aconteciam os encontros dos jovens, e os grupos se formando, reunindo-se quase sempre nos mesmos espaços da escola. Segundo Pais, as culturas juvenis, além de serem socialmente construídas, "têm também uma configuração espacial” (PAIS, 1993, p. 118).

Para tratar da análise dos relatos do campo, optamos por abordá-los a partir dos eixos temáticos, tendo presente também algumas falas dos grupos para destacar a importância destes sujeitos no espaço/tempo da escola.

\subsection{Aproximações e a formação do grupo: encontros e desencontros}

Neste eixo temático, abordamos como se deu a aproximação dos alunos desde a chegada na escola. Os grupos são marcados por algumas diferenças, suas identidades. $\mathrm{O}$ fato de alguns alunos já se conhecerem pode ter sido um facilitador para alguns grupos, como o Fashion, o Jeanswear e o Moda Rock. Para os demais alunos, a 
necessidade de conquistar um espaço e se aproximar de alguém que tivesse afinidades com suas maneiras de pensar, ser e agir foi marcante para formação do grupo: "Eu vi a necessidade de me juntar logo com um grupo assim, porque já estava em abril " [...] já, assim, quase na metade de abril. Eu já vi, assim, vou me juntar com um grupo logo, pra mim já ter uma, uma referência assim. (integrante do Grupo Sportwear)

\subsection{Interesses comuns: caracterização e identificação como grupo}

A identificação como grupo é dada de diferentes formas, pois cada grupo tem seus símbolos, suas identidades e assim constroem suas identificações. Mas a música é um dos itens que marca a identidade dos grupos, aliada ao desenho, filmes, estilo de vestir e o companheirismo, itens que aparecem nas falas dos diferentes grupos e que os caracterizam: "Todo mundo ali é fissurado por esses desenhos animados. Aí, assim, a gente vai encontrando jeitos, música. Eu não[...] Eu tenho gostos bem parecidos com os deles. A Cris é que tem gostos assim mais diferentes. Eu tenho gostos bem parecidos com os deles. Tem algumas coisas que eu gosto, tem outras que não. Natural em qualquer grupo. Mas, mas tirando isso, a gente não fala só desses assuntos, a gente fala de nossa vida particular, assim, relacionamento com outras pessoas". (integrante do Grupo Moda Rock)

"A moda/indumentária serve tanto para aproximar quanto para manter distância. Isto fica visível no cotidiano escolar, em que os sujeitos de cada grupo têm características bem parecidas, conforme o gosto e os símbolos que cada grupo tem ou com os quais se identifica: Nossos estilos, nossas roupas é nossa identidade". (integrante do Grupo Moda Rock). "Quando eu fui conversar com o Bené, primeira vez, ai eu olhei ele assim, olhei bem assim. "Ele não deve ser aquele tipo malacol que eu não gosto". Assim, entendeu, eu não gosto desse tipo malaco, assim. Ai, pô, eu olhei bem ele, assim. "Pô, não deve ser, eu vou conversar com ele, ele deve ser gente fina", assim”. (integrante do Grupo Sportwear)

${ }^{1}$ Segundo os jovens, "malaco" é aquele jovem que veste roupa toda largada, com a calça caída, boné na diagonal, tênis grande. 


\subsection{Identidades corporais provisórias: moda/indumentária como facilitador para a formação dos grupos}

A moda/indumentária foi reconhecida pelos sujeitos da pesquisa como um símbolo de comunicação. Se ela é uma das formas de comunicação que está presente em nossa sociedade há muito tempo, isso não é diferente no espaço escolar. Além de atuar como um símbolo de comunicação, a moda/indumentária é também um dos itens de consumo dos jovens que demonstram sua preocupação em estar na moda, e alguns desses sujeitos dizem ter na vestimenta um dos símbolos de diferenciação: "Porque pela vestimenta, assim, se faz[...] Pela indumentária do cara, se faz um pré-julgamento dele, né. Isso é errado, assim, lógico. Mas é uma coisa inconsciente. Assim, por exemplo, se vê um "ferrado" todo assim. Não vai ser uma coisa meio compativel assim. Vai ser diferente”. (integrante do Grupo Sportwear)

\subsection{Outros símbolos comunicacionais e identitários: os adereços}

O uso dos adereços é um dos itens que gera certas divergências entre grupos e até mesmo entre alguns alunos do próprio grupo. Pois enquanto alguns sujeitos do grupo gostam de adereços e os usam, outros apenas os admiram, mas dizem que não usariam. "É, este aqui é um símbolo egípcio, né. Como eu tava falando, daí, sei lá, tá relacionado... Eu gosto, enfim... Tem o Franco que também tem uma dessa. Assim, todo mundo vai bem lá. Dai vai descobrindo as afinidades mesmo, os gostos que se batem. Mas tu vai descobrindo a partir do convívio. Não por causa deste símbolo que se aproximou deles. Mas foi descobrindo que a gente tinha mesmo alguns gostos parecidos, a partir do convívio, de conversas [...] Se todo mundo ficasse quieto, ninguém conversasse, ninguém ia descobrir que era parecido ou não, né”. (integrante do Grupo Moda Rock)

\subsection{O uniforme escolar: disputa e negação de identidade}

Conforme Barnard (2003), o uso do uniforme tem um objetivo que é o da instituição mostrar seus valores para além dos muros, isto está presente desde as cores, 
os modelos. A escola em que foi realizada a pesquisa não adota o uso do uniforme, sendo que a grande maioria dos alunos concorda com o não uso do uniforme. Entendem que assim eles têm a oportunidade de mostrar suas identidades e por conseqüências construírem seus grupos mais depressa, para eles uma das únicas justificativas para o uso do uniforme seria quanto à questão econômica. $\mathrm{O}$ fato de não usar uniforme dá mais liberdade de expressão para os jovens. A escola procura comunicar, por meio do uso do uniforme, sua organização, sobriedade, austeridade, sua erudição: "Mais liberdade, né, de se expressar, sabe, pode botar a roupa que tu quer, quando tem uniforme se sente mais presa, mais parece que tão mandando em ti". (integrante do Grupo Jeanswear)

\subsection{Moda/indumentária das diferenças: a presença (nem sempre) sutil de preconceitos}

O preconceito é o único eixo temático que não foi apontado preliminarmente, tendo surgido nas conversas com alguns dos grupos focais. E o que cabe enfatizar é que muitas vezes a naturalidade e/ou simplesmente o não perceber dessas atitudes, esconde ou camufla a forma como se dirigem aos diferentes. Na negação da aproximação pela forma de vestir, ou pelos gostos dos sujeitos, o preconceito pode estar presente, mesmo que seja negado: "Acho que facilitou, né, é porque se tivesse uniforme a gente não teria como fazer esse pré-conceito. Pré-conceito não precisa necessariamente ser uma discriminação, tá ligado, mas com uniforme todo mundo igualzinho, assim, não teria como fazer essa escolha, assim teria que dar um baita de um chute". (integrante do Grupo Sportwear)

\section{CONSIDERAÇÕES FINAIS}

É necessário destacar que o presente estudo enfrentou as dificuldades inerentes a uma temática pouco desenvolvida no cotidiano escolar, que são os estudos sobre as culturas juvenis não focados exclusivamente no processo ensino-aprendizagem. Além disso, o recorte procedido para estudos dos jovens-alunos, relativo à compreensão da moda/indumentária como identidade corporal provisória e símbolo de comunicação, 
exigiu esforços extras para estabelecer um diálogo entre o núcleo de senso comum a este respeito - tão presente nos estudos sobre o cotidiano - e os muitos aportes teóricos que vêm do campo das ciências humanas e sociais. Reconhecemos também a necessidade de que outros estudos sejam desenvolvidos, com outros símbolos presente no cotidiano juvenil, para termos mais subsídios e conhecermos um pouco mais sobre esses sujeitos que estão presentes nos espaços escolares.

Nesta pesquisa, podemos considerar que foram obtidas informações relevantes mesmo que referidas a um grupo restrito e não generalizáveis ao universo dos jovens sobre como os jovens pensam seus espaços; sua importância simbólica social; a construção destes novos espaços e das formas de interação; a formação dos grupos e a inserção dos jovens nos grupos formados.

Pensar as questões que dizem respeito aos jovens a partir de suas pluralidades é de fundamental importância para que possamos suprir um pouco a carência de estudos que tratem das mais variadas formas simbólicas de os jovens se constituírem enquanto grupos. Compreender as culturas juvenis dentro e fora dos espaços estabelecidos como formais pela sociedade é uma das maneiras de buscar uma interação com estes sujeitos e, assim, constituir um ambiente que possibilite aos jovens o exercício de suas potencialidades humanas. Os jovens têm no espaço/tempo escolar, para além da sala de aula, um momento importante: trata-se do momento de construção das relações sociais com múltiplas mediações e interesses, voltados para as necessidades pessoais e os vínculos sociais e afetivos. Nesses espaços/tempos, os jovens constituem seus grupos, tendo como um dos símbolos de comunicação que propicia esta aproximação a moda/indumentária, como identidade que portam. A moda/indumentária representa um aparato social que se constitui num símbolo de comunicação presente nas relações intersubjetivas.

Embora a escola, como espaço social, normalmente ignore esse processo comunicacional, não é assim que os jovens desta pesquisa o percebem. Para eles, a moda/indumentária é percebida como um símbolo de comunicação presente no cotidiano escolar. De acordo com as falas dos sujeitos da pesquisa, não restam dúvidas de que a moda/indumentária, como um dos símbolos de comunicação, tem fundamental 
importância para que os jovens possam, intersubjetivamente, expressar suas identidades e buscar a construção de seus grupos, conforme seus símbolos de pertencimento.

No que se refere à comunicação, temo-la presente no corpo como mídia primária, e a moda/indumentária e adereços como mídia secundária, conforme vimos em Baitello Júnior (2000). Na verdade, essas duas instâncias se fundem naquilo que ao longo do texto denominamos identidades corporais provisórias. Esse embaralhamento entre as duas formas de comunicação se confirmou na pesquisa, conforme as falas dos sujeitos. É importante ressaltar que os grupos estão presentes tanto no espaço escolar como fora dela. Como relatam alguns jovens, seus grupos se encontram nos finais de semanas, nos shoppings ou em outros espaços de convívio social.

Conforme Dayrell (2003, p. 185), "a estrutura escolar e os projetos políticopedagógicos ainda dominantes nas escolas não respondem aos desafios que estão postos para a educação da juventude contemporânea". Desta forma, o que cabe à escola, diante das dicas e sugestões dos jovens expressas na pesquisa, é buscar a compreensão e interação com estes sujeitos em todo o espaço escolar, não apenas na sala de aula, valorizando os aspectos socioculturais constituintes de suas identidades.

Vale ainda observar que os jovens gostam da escola, mesmo com suas contradições; eles têm no espaço/tempo da escola um local que lhes proporciona uma interação com seus pares. Eles buscam um diálogo com a escola por meio de sua maneira de se comunicar. É preciso acreditar que cada sujeito pode contribuir para construção das regras de convívio coletivo e não simplesmente cumpri-las. Para Dayrell (2003, p. 186), “a escola pouco conhece o jovem que a freqüenta, a sua visão de mundo, os seus desejos, o que faz fora da escola, como ocupa seu tempo livre e as expressões culturais com as quais se envolve”. A escola deve ser um local que não só permita, mas também incentive e interaja com as questões socioculturais de seus sujeitos e que reconheça a unidade na diversidade e vice-versa, e isto pode estar nos grupos. Deve ser um espaço de encontro, de estímulo à sociabilidade, que permita vivenciar a construção coletiva das normas, criando estratégias de acesso, pertencimento, permanência e qualidade, pautadas no respeito ao outro e na inclusão de todos. 


\section{Abstract}

This research aimed to comprehend communication within juvenile cultures, expressed by means of symbols of fashion/clothing and ornaments in a school environment, taking into account the students' sociocultural aspects, their different groups and cultures. To reveal the existence of those groups within the school spaces seems to be highly necessary, for the school to be able to perceive them and, maybe, search for ways of interaction and recognition. The research points to the need for the school to regard adolescents as subjects of their daily life, including school, not limiting to establish norms and to recognize them only within the space-time of the classes, because it's in that space where they show their identities, establishing their groups and auto recognize.

Key-Words: Fashion/clothing; Juvenile cultures; Communication; Body identities.

\section{Referências Bibliográficas}

ABAD, M. Crítica política das políticas de juventude. In: FREITAS, M. V.; PAPA, F.

C. Políticas públicas: juventude em pauta. São Paulo: Cortez: Ação Educativa Assessoria, 2003.

ABRAMO, H. W. Cenas juvenis. São Paulo: Scritta, 1994.

AGUIAR, V. T. O verbal e o não verbal. São Paulo: Ed. da UNESP, 2004.

BAITELLO JÚNIOR, N. O tempo lento e o espaço nulo: mídia primária, secundária e terciária. 2000. CISC. Disponível em: www.cisc.org.br. Acesso em: 22 mar. de 2005.

BARNARD, M. Moda e comunicação. Rio de Janeiro: Rocco, 2003.

BRENNER, A. K.; DAYRELL, J.; CARRANO, P. Culturas do lazer e do tempo livre dos jovens brasileiros. In: ABRAMO, H. W.; BRANCO, P. P. M. Retratos da juventude brasileira: análise de uma pesquisa nacional. São Paulo: Perseu Abramo, 2005 .

CASTILHO, K. Moda e linguagem. São Paulo: Anhembi Morumbi, 2004.

CASTRO, M. G; ABRAMOVAY, M. Por um novo paradigma do fazer políticas: políticas de/para/com juventude. Brasília: UNESCO, 2003. 
COSTA, A. G. Moda/indumentária em culturas juvenis: símbolos de comunicação e formação de identidades corporais provisórias em jovens de ensino médio. 2006. Dissertação (Mestrado em Educação Física) - Faculdade de Educação Física, Universidade Federal de Santa Catarina, Florianópolis, 2006.

DAYRELL, J. Escola e culturas juvenis. In: FREITAS, M. V. de; PAPA, F. de C. (Org.). Políticas públicas: juventude em pauta. São Paulo: Cortez; 2003.

. A música entra em cena: o rap e o funk na socialização da juventude. Belo Horizonte: Ed. da UFMG, 2005.

LURIE, A. A linguagem das roupas. Rio de Janeiro: Rocco, 1997.

PAIS, J. M. Culturas juvenis. Lisboa: Imprensa Nacional: Casa da Moeda, 1993.

SACRISTAN, J. J. Poderes instáveis em educação. Porto Alegre: Artes Médica, 1999.

SOARES, L. E. Juventude e violência no Brasil contemporâneo. In: NOVAES, R. V. P. (Orgs.). Juventude e sociedade: trabalho, educação, cultura e participação. São Paulo: Perseu Abramo, 2004.

THOMPSON, J. B. Ideologia e cultura moderna: teoria social crítica na era dos meios de comunicação de massa, 6. ed. Petrópolis: Vozes, 1995.

TREBELS, A. H. Uma concepção dialógica e uma teoria para o movimento humano. Revista Perspectiva. v. 21, n. 1, jan./jun. 2003. 